\title{
Analysis of the effect of risk management practices on the performance of new product development programs
}

\author{
Oehmen, Josef; Olechowski, Alison; Kenley, C. Robert; Ben-Daya, Mohamed
}

Published in:

Technovation

Link to article, DOI:

10.1016/j.technovation.2013.12.005

Publication date:

2014

Link back to DTU Orbit

Citation (APA):

Oehmen, J., Olechowski, A., Kenley, C. R., \& Ben-Daya, M. (2014). Analysis of the effect of risk management practices on the performance of new product development programs. Technovation, 34(8), 441-453.

https://doi.org/10.1016/j.technovation.2013.12.005

\section{General rights}

Copyright and moral rights for the publications made accessible in the public portal are retained by the authors and/or other copyright owners and it is a condition of accessing publications that users recognise and abide by the legal requirements associated with these rights.

- Users may download and print one copy of any publication from the public portal for the purpose of private study or research.

- You may not further distribute the material or use it for any profit-making activity or commercial gain

- You may freely distribute the URL identifying the publication in the public portal 


\title{
Analysis of the effect of risk management practices on the performance of new product development programs
}

Josef Oehmen $^{\mathrm{a}, \mathrm{b}}$, Alison Olechowski ${ }^{\mathrm{a}}$, C. Robert Kenley ${ }^{\mathrm{c}}$ and Mohamed Ben-Daya ${ }^{\mathrm{d}}$

${ }^{a}$ Technical University of Denmark

${ }^{\mathrm{b}}$ Massachusetts Institute of Technology

${ }^{\mathrm{c}}$ Purdue University

${ }^{\mathrm{d}}$ King Fahd University of Petroleum and Minerals

\section{Highlights}

- Investigates the association between risk management practices and new product development program performance

- Based on extensive empirical data collected through survey

- Presents new framework to define risk management success in NPD programs

- Identifies six categories of risk management practices associated with success

- Out of 95 analysed risk management "best practices", only 30 show significant associations with success.

\begin{abstract}
Risk management is receiving much attention, as it is seen as a method to improve cost, schedule, and technical performance of new product development programs. However, there is a lack of empirical research that investigates the effective integration of specific risk management practices proposed by various standards with new product development programs and their association with various dimensions of risk management success. Based on a survey of 291 new product development programs, this paper investigates the association of risk management practices with five categories of product development program performance: A. Quality Decision Making, B. High program stability; C. Open, problem solving organization; D. Overall NPD project success and E. Overall product success. The results show that six categories of risk management practices are most effective: 1. Develop risk management skills and resources; 2. Tailor risk management to and integrate it with new product development; 3. Quantify impacts of risks on your main objectives; 4. Support all critical decisions with risk management results; 5. Monitor and review your risks, risk mitigation actions, and risk management process; and 6. Create transparency regarding new product development risks. The data shows that the risk management practices are directly associated with outcome measures in the first three categories (improved decision making, program stability and problem solving). There is also evidence that the risk management practices indirectly associate with the remaining two categories of outcome measures (project and product success). Additional research is needed to describe the exact mechanisms through which risk management practices influence NPD program success.
\end{abstract}

\section{Keywords}

Risk management, new product development, program management 
Manuscript (Final Revision): Effect of Risk Management Practices

\section{Introduction to risk management in new product development}

\subsection{The importance of risk management in new product development programs}

There are several definitions of risk depending on the application. In decision theory, risk is related to making decisions under known probabilities of the states of nature (Luce and Raiffa, 1957). In economic theory, risk arises when the decision maker can assign probabilities to possible outcomes (Knight, 1921). A well accepted definition of risk given in projected management body of knowledge considers risk as "an uncertain event or condition that, if it occurs, has a positive (opportunity) or negative (threat) impact on project objectives" (PMI, 2008). However, for most practitioners project risk management seems to be about identifying and managing threats. For NPD, we follow the ISO 31000 definition (ISO, 2009) which defines risk as the effect of uncertainty on achieving the NPD objectives.

New product development is inherently linked to taking and managing risks (e.g. Baba et al., 1995; Kwak and LaPlace, 2005), as most activities can be interpreted as a structured reduction of uncertainty. Studies of customer needs and market trends reduce the uncertainty surrounding requirements; technology development, testing and evaluation create certainty regarding the capabilities and cost of new technologies, and the improvement and standardization of NPD processes within the organization increases the reliability of executing the development process (Mu et al., 2009). Reducing risks in new product development can also increase customer value (Browning et al., 2002), and can be used as a lens to analyze and optimize product development processes (Oehmen and Seering, 2011). More generally, improving the "risk-return balance" is a central tenant of business decision making, from project portfolio choices (Floricel and Ibanescu, 2008) to business strategy and investment allocation (Fama and Macbeth, 1973).

There is also evidence that new product development suffers from risks, and is prone to serious cost and schedule overruns, as well as problems in achieving the targeted technical performance of the product (GAO, 2010). In the related field of software development, average cost overruns of projects are reported on the order of 30-40\% (see Jørgensen and Moløkken-Østvold, 2006 for a detailed discussion). Similarly, in complex infrastructure construction projects, average cost overruns are quoted in the range of $28-50 \%$, with up to $77 \%$ of projects experiencing cost overruns (see Cantarelli et al., 2010 and references therein). Of particular relevance are findings of the US Government Accountability Office that analyses the success of engineering programs, among them new product development programs, of the US Department of Defense (GAO, 2010, 2006). While all engineering programs (including those that focus on production or life-cycle 


\section{Manuscript (Final Revision): Effect of Risk Management Practices}

management) suffer from an average cost overrun of $25 \%$, those programs that focus on new product development show an average cost overrun of $42 \%$ and schedule delay of 22 months (GAO, 2006).

\subsection{NPD risk management literature}

There is a vast literature dealing with various aspect of risk management in NPD that cannot be covered in detail in this paper. The reader may find more details in a recent review (Oehmen et al., 2010). In this section, we simply highlight the literature dealing with types of NPD risks and their classification. The relationship of risk management with success on NPD projects is discussed in Section 1.3 and relevant risk management processes frameworks for NPD are discussed in

\section{Section 2 .}

One of the most comprehensive collections of NPD risks is presented by Keizer et al. (2005) based on a literature survey and case studies in the fast-moving consumer goods industry. A list of 142 R\&D program risks is grouped in 12 categories (commercial viability, competitor, consumer acceptance and Marketing, public acceptance, intellectual property, manufacturing technology, organization and project management, product family and brand positioning, product technology, screening and appraisal, supply chain and sourcing, and trade customer risks). Persson et al. (2009) also develops an extensive list of development project risks based on a literature review, presented in 8 risk areas (task distribution, knowledge management, geographical distribution, cultural distribution, stake holders relations, communication infrastructure, and technology setup) divided into 24 risk factors. Jiang \& Klein (2000) develop a risk collection for software development projects, falling into 12 project risk categories (technological acquisition, project size, five categories dealing with team expertise and communication, lack of user support and experience, and application complexity) containing 49 risks. (Sicotte and Bourgault, 2008) identify four types of risks (technical and project uncertainty, market uncertainty, fuzziness and complexity) that impact R\&D project effectiveness and efficiency, as well as a co-moderating effect of project methods and human resources. Focusing on radical innovation projects, O'Connor and Rice (2013) recommend project management focus on four more general key areas of uncertainty: technical, market, organizational and resource. (Yeo and Ren, 2008) develop a conceptual model and framework for risk management maturity. As part of their model, they postulate four categories of risk, relating to processes, organization, technology and the environment. These categories were developed based on the analysis of 51 published project cases. Based on a literature review, Park (2010) identified 24 risk factors in 5 categories: operational, technology, organizational market and 


\section{Manuscript (Final Revision): Effect of Risk Management Practices}

supplier risks. The following paper addresses riska in a particular application in the aerospace industry. Addressing the latest overheating batteries problem that grounded the Boeing Dreamliner 787 at the beginning of 2013, Denning (2013) identified several risks that plagued the project including coordination, innovation, outsourcing, partially implementing the Toyota model, offshoring, communication by computer, labor relations. Project management skills, and disengaged top management risks. The article concludes with some recommendations for Boeing. Another study looked at a particular risk, namely the risk of customer integration (also see Tang and Zimmerman, 2009). In their study, Song et al. (2013) focused on the risk evaluation of customer integration in NPD. Potential risks include loss of know-how, much dependence on customer, and limitations to incremental innovations. They proposed an evaluation approach for assessing customer integration risk and applied it in a project for mobile phone development

\subsection{Existing empirical investigations of risk management in NPD}

A number of prior studies have pointed out that risk management in general is an important contributor to new product development program success: For example, $\mathrm{Mu}$ et al. (2009) show that risk management strategies targeting technological, organizational and marketing risk factors improve NPD performance individually and interactively. The study by Jacob and Kwak (2003) highlights the positive contribution of risk management to improve project selection, review and resource allocation of NPD projects. In their investigation of over 100 technology-related projects, Raz et al. (2002) show that the use of risk management practices contribute to project success. In a recent large scale survey of 700 project managers on risk management in general project management, Zwikael and Ahn (2011) showed that even moderate risk management efforts increased project performance. Also, a recent study carried out by one of the authors indicates that a lack of proper risk management is one of the 10 major challenges that plague large-scale new product development programs, and that conversely the introduction of efficient risk management practices is a contributor to increased performance (Oehmen et al., 2012).

Wirthlin (2009) used empirical data to model the US defense acquisition system as three interdependent processes: budgeting (how much and when to buy), requirements development (why and what to buy), and acquisition (how to buy). He defined five key characteristics of the acquisition system: cost, schedule, quality, transparency, and flexibility. He concluded that flexibility, transparency, and quality are the most valued and are essentially non-negotiable, whereas cost and schedule are negotiable. He describes the behaviors and results that occur from valuing these three characteristics as 


\section{Manuscript (Final Revision): Effect of Risk Management Practices}

follows: If flexibility is valued, e.g. being able to start programs at will, rush things through, jump ahead of other programs in development cycle, then the system must be able to deal with the funding instability that ensues. If transparency is valued, e.g. process checking, error-proofing, consensus-building, then the system must maintain process reviews and levels of approval and accept expensive use of calendar time. If quality is valued, e.g. not giving relief for technical requirements, capabilities and performance expectations, then expect program delays and cost increases to develop and mature the necessary technologies, or deliver the expected capabilities, etc.

Other studies have focused on investigating particular risk management methods and risks: Based on a review of the literature, Kwak and Stoddard (2004) synthesize both risks as well as "lessons learned" for effective risk management. Realizing the importance of control of risks to the sustained success of risk management, Zentis and Schmitt (2013) suggested an integrated model for assessment and control of technical risks. The model was validated using a practical application in the medical industry. Thamhain (2013) conducted a study dealing with risk management practices of 35 PD projects in 17 high technology companies. It was observed that almost half of the risks that occur are not being detected before they impact project performance. The field data suggests that success scenarios point to the critical importance of recognizing and dealing with risks early on. This involves broad involvement and collaboration across all segments of the project team and its environment. Specific managerial actions, organizational conditions, and work processes are suggested for fostering a project environment conducive to effective cross-functional communication and collaboration among all stakeholders that help early risk detection and effective risk management in complex projects. Wang et al. (2010) propose a method to link risk management activities in NPD projects via a balanced scorecard and quality function deployment to corporate and project strategy. Two specific methods to facilitate decision making under uncertainty are the focus of the paper by Doctor et al. (2001), i.e. decisions trees and option pricing theory. Candi et al. (2013) examine the effect of technological turbulence on innovation projects, and the potential for project flexibility to mitigate this uncertainty. Focusing on the nano-textiles and smart textiles industries, Köhler and Som (2013) recommend strategies for anticipating and managing environmental and safety risk. Based on 266 NPD projects from three industries in nine countries, Ahmad et al. (2013) looked at the effect of two dominant NPD best practices: concurrent PD process and integrated PD teams and concluded that neither of these best practices should be adopted universally. They concluded that process concurrency should be avoided in projects with high uncertainty and team integration should be encouraged for complex PD projects. The PD practice should be determined by the NPD project characteristics rather than one-size-fits- 
Manuscript (Final Revision): Effect of Risk Management Practices

all solutions. Drawing on ideas from the organization theory and learning literatures, Carson et al. (2012) proposed a theory describing how uncertainty due to ambiguity and volatility affect NPD process. They suggest that more ambiguous environments favor slow development processes wherea more volatile environments favor faster and more flexible PD processes. Tested hypotheses suggest that as the level of ambiguity increases (decreases) relative to the level of volatility, firms should respond by decreasing (increasing) the role of top management in NPD and increasing (decreasing) front-end and back-end participation allocation more (less) time and effort to ideation, and using more (less) aggressive screening processes. Their theory was tested using 120 new products and their subsequent performance.

\subsection{Contribution of this paper}

The literature discussed above suggests that better risk management leads to improved new product development program success. Also, a number of specific methods in the context of risk management have been investigated and their effectiveness highlighted.

However, the literature does not document any empirical investigations of how risk management activities can be effectively and efficiently implemented and integrated in new product development. This paper closes this gap by collecting suggested best practices from the academic literature as well as an industry focus group, and investigating their statistical relationship with overall risk management performance of NPD programs through a survey. To that end, the paper also investigates how risk management performance can be characterized other than by overall program performance and takes a very differentiated look at the various aspects in which risk management activities make a positive contribution.

The remainder of the paper is organized as follows: Section 2 summarizes existing recommendations on risk management practices in new product development. Section 3 outlines the research method, in particular the survey design and the statistical methods used for the data analysis. Section 4 describes the results: Section 4.1 presents measures for risk management outcomes in new product development programs, section 4.2 describes risk management practices that were

found to correspond with increased risk management success, and section 4.3 summarizes what risk management outcomes are associated with the most risk management practices. The discussion in section 5 summarizes the results, highlights the practical applicability of our findings, and identifies open research questions and limitations of this study. 


\section{Existing recommendations on risk management practices in new product development}

A number of management philosophies exist when it comes to new product development that focus on managing different types of risks, but do not explicitly address risk management as such (Bassler et al., 2011): For example, classical waterfall models of product development focus on minimizing risks associated with integrating the development of complex systems, while spiral development models are targeted at managing risks associated with unclear and changing requirements. Design for Six Sigma emphasizes up-front risk assessment to identify sensitive system components, but does not offer a comprehensive risk management framework.

On the other hand, a number of risk management frameworks exist that are applicable to new product development (see Table 1 for a comparison of the different risk management process steps).

The ISO 31000 standard (ISO, 2009) is a generic framework for managing risks. Its aim is to be independent of any specific application context, and therefore does not address new product development explicitly. Risk is defined as the effect of uncertainty on objectives. Risk management in turn is broadly defined as coordinated activities to direct and control an organization with regard to risk.

The project management literature offers a number of risk management frameworks, for example as part of the PMI Project Management Body of Knowledge (PMI, 2008) or the PRINCE2 project management framework (OGC, 2009). The focus is on project management-related risks (such as cost and schedule), but also addresses other organizational risks, external risks as well as technical risks. Risk management aims to protect against negative impacts on scope, schedule, cost and quality.

There are also a number of risk management standards that explicitly focus on the development of technology-driven products and systems, such as NASA's Risk-Informed Decision Making Handbook (Dezfuli et al., 2010), the Risk Management Guide for Acquisitions of the US Department of Defense (DoD, 2006), and the risk management procedures described in INCOSE's Systems Engineering Handbook (INCOSE, 2007).

In NASA's handbook, risk is defined as the potential for performance shortfalls of the system under development. Risk management is defined as a set of activities aimed at achieving success by proactively risk-informing the selection of 


\section{Manuscript (Final Revision): Effect of Risk Management Practices}

decision alternatives and then managing the implementation risks associated with the selected alternative. It considers safety, technical, cost, and schedule risks.

The US Department of Defense's risk management guide defines risk as a measure of future uncertainties in achieving program performance goals and objectives within defined cost, schedule, and performance constraints. Risk management itself is defined as an organized methodology to carry out the risk management process. It considers a wide range of risks, from requirements stability, technical baseline planning, execution of various product development steps, external influences, as well as resulting cost and schedule implications.

The INCOSE risk management standard discerns between risk management of development projects and environmental and safety-related risk management. Risk is defined as a measure of the uncertainty of attaining a goal, objective, or requirement pertaining to technical performance, cost, and schedule. It defines risk management as a continuous process for systematically addressing risk throughout the life cycle of a system, product or service, including contracting, development and operation of a product or system. The types of risks that are explicitly addressed are technical, cost, schedule, program, and project management, as well as support during operation.

The Software Engineering Institute (SEI) risk management paradigm (Gallagher, 1999) defines a systematic process for managing a project's risks. The process consists of a number of functions that are performed as continuous activities throughout a project's life cycle. It is geared towards software projects.

Table 1 shows two important aspects. First, all frameworks have similar process steps. Second, the process framework proposed by ISO 31000 can serve as a "common denominator" to collect and consolidate risk management practices from the various sources. This framework was used during the design of the survey instrument (see Section 3.1). 
Manuscript (Final Revision): Effect of Risk Management Practices

Table 1: Comparison of risk management process steps under various frameworks

\begin{tabular}{|c|c|c|c|c|c|}
\hline ISO 31000 & PMI & NASA & DoD & INCOSE & SEI \\
\hline $\begin{array}{l}\text { Communication and } \\
\text { consultation }\end{array}$ & Implicit & $\begin{array}{l}\text { Communicate } \\
\text { document }\end{array}$ & Implicit & Planning & Communicate \\
\hline $\begin{array}{l}\text { Establishing the } \\
\text { context }\end{array}$ & Plan RM & Implicit & & & Implicit \\
\hline Risk identification & Identify risks & Identify & Risk identification & $\begin{array}{l}\text { Risk } \\
\text { identification }\end{array}$ & identify \\
\hline Risk Analysis & Risk analysis & Analyze & Risk Analysis & Risk Assessment & Analyze \\
\hline \multicolumn{6}{|l|}{ Risk Evaluation } \\
\hline \multirow[t]{2}{*}{ Risk treatment } & \multirow[t]{2}{*}{$\begin{array}{l}\text { Plan risk } \\
\text { response }\end{array}$} & \multirow[t]{2}{*}{ Plan } & $\begin{array}{l}\text { Risk mitigation } \\
\text { planning }\end{array}$ & Risk Analysis & Plan \\
\hline & & & $\begin{array}{l}\text { Risk mitigation plan } \\
\text { implementation }\end{array}$ & Risk Handling & \\
\hline $\begin{array}{l}\text { Monitoring and } \\
\text { review }\end{array}$ & $\begin{array}{l}\text { Monitor and } \\
\text { control risks }\end{array}$ & Track & Risk tracking & & $\begin{array}{l}\text { Track } \\
\text { Control }\end{array}$ \\
\hline
\end{tabular}

\section{Research Method}

\subsection{Survey design and data collection}

The findings reported in this paper are based on a survey that was developed and tested over a period of six months (October 2010 - March 2011) with a focus group consisting of twelve individuals from three academic institutions, one risk management consultancy from the aerospace sector, and six companies from the aerospace and defense sector. All participants were based in the United States, except one participant based in the Kingdom of Saudi Arabia.

The development of the survey relied on an extensive review of the pertinent literature (for a list of key sources, please see discussion in Section 2) to identify suggested "best practices" in risk management. During the testing of the questionnaire, we aimed to reduce the overall length of the survey. In some cases, this included eliminating a practice that had been suggested by the literature, when there was unanimous agreement among the subject matter experts that this practice was not effective in industry application.

This resulted in a survey with 171 questions in four main categories (see Table 2), 49 of which were not analyzed for this paper. The data contained in those responses is not relevant to the focus of this analysis, and so it will be left to future work. The total time needed to complete the survey was approximately 45-60 minutes. The unit of analysis was clearly defined for the respondents as their last completed new product development program. 
Two strategies were applied to maximize the number of respondents: The survey was distributed through the risk management organization of six large aerospace and defense companies and one government organization in the same area as part of a benchmarking process. This yielded 90 respondents.

The second strategy focused on the distribution to a wider circle of recipients via professional organizations and their mailing lists in the area of risk management in NPD programs, and the survey was tailored to two groups of respondents. Respondents were assigned to either the "Program Manager" or "Risk Manager" group, based on the function in the development program they indicated at the beginning of the survey. As the survey was conducted online, the respondents that were binned into the "Risk Manager" category were randomly assigned to one of the two risk management groups (A or B) to further limit the overall length of the survey for each respondent, with an equal distribution between the groups. Group A answered sections 3.1, 3.3 and 3.6, whereas Group B answered sections 3.2 and 3.5. All respondents answered sections 1, 2, 3.4 and 4 (see Table 2). Program managers (i.e. respondents not working in a dedicated risk management role) in addition answered section 3.1.

Table 2: Structure of the Survey

\begin{tabular}{|c|c|c|c|c|c|c|c|c|c|}
\hline \multirow[t]{2}{*}{ Survey Sections } & \multirow[t]{2}{*}{$\begin{array}{l}\text { \# of } \\
\text { questions }\end{array}$} & \multicolumn{4}{|c|}{ Respondent group } & \multicolumn{3}{|c|}{$\begin{array}{l}\text { Median \# of } \\
\text { valid responses }\end{array}$} & \multirow{2}{*}{$\begin{array}{l}\text { Thereof \% } \\
\text { risk } \\
\text { managers }\end{array}$} \\
\hline & & 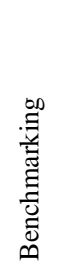 & 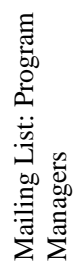 & 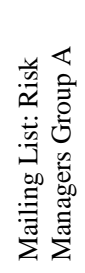 & 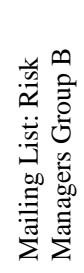 & స్ & 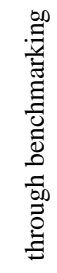 & 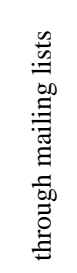 & \\
\hline 1. Characteristics of the organization & 5 & $\mathrm{X}$ & $\mathrm{X}$ & $\mathrm{X}$ & $\mathrm{X}$ & 291 & 90 & 201 & $24 \%$ \\
\hline \multirow{2}{*}{\multicolumn{10}{|c|}{ 3. Risk management practices }} \\
\hline & & & & & & & & & \\
\hline 3.1 Planning \& preparation & 24 & $X$ & $\mathrm{X}$ & $X$ & & 197 & 90 & 107 & $15 \%$ \\
\hline 3.2 Risks and their impact $(*)$ & 21 & $\mathrm{X}$ & & & $\mathrm{X}$ & 130 & 90 & 40 & $27 \%$ \\
\hline 3.3 Risk analysis & 11 & $\mathrm{X}$ & & $\mathrm{X}$ & & 105 & 90 & 15 & $25 \%$ \\
\hline 3.4 Risk evaluation & 8 & $X$ & $\mathrm{X}$ & $X$ & $X$ & 227 & 90 & 137 & $21 \%$ \\
\hline 3.5 Risk treatment & 32 & $X$ & & $X$ & & 119 & 90 & 29 & $26 \%$ \\
\hline 3.6 Risk monitoring & 20 & $\mathrm{X}$ & $\mathrm{X}$ & & & 112 & 90 & 22 & $27 \%$ \\
\hline 4. Risk management performance & 22 & $X$ & $\mathrm{X}$ & $\mathrm{X}$ & $X$ & 215 & 90 & 125 & $19 \%$ \\
\hline
\end{tabular}

$(*)$ : Not analyzed in this paper

In total, 381 responders finished the survey over a period of six months (March - September 2011), yielding 291 valid datasets. This includes 90 complete datasets of the survey that were collected through the benchmarking deployment 


\section{Manuscript (Final Revision): Effect of Risk Management Practices}

previously discussed. The remaining 201 partial datasets were obtained by distributing the survey through mailing lists of professional organizations. In these datasets, the respondents were guided through different parts of the survey, based on their role (as explained above). Second, respondents were allowed to skip questions, if the answer was unknown to them or if they were not comfortable answering the question due to confidentiality concerns. The sample size thus varies for the different sections of the survey (see Table 2) between 112-291 responses. Exact response rates are difficult to ascertain, as the survey was distributed through organization-internal channels due to confidentiality measures, and recipients were encouraged to forward the survey invitation to colleagues. We estimate the response rates through the benchmarking activities at approximately $40 \%$, and the response rate through mailing lists of risk management professionals at approximately $5 \%$.

Through both channels (benchmarking and professional organizations), we targeted individuals that had direct and significant involvement in risk management activities in their programs, both in risk management and other management roles. While we cannot assess the influence of self-selected participation on the responses, we believe that explicitly selecting and targeting respondents with direct involvement in risk management activities contributes significantly to the validity of our findings.

Table 3 shows that about half of the survey respondents are from the aerospace \& defense sector (51\%), whereas the remaining $49 \%$ are distributed among other industries. Our interpretation of this skewed sample distribution is that the formal application of risk management practices is strongest in this industry sector and representatives from this industry were thus strongly represented in the professional organizations that distributed the survey, which aligns with the personal experience of the authors. A preliminary analysis of the data did not show significant industry-specific differences for the purposes of this paper. The size of the organizations of the respondents is relatively evenly distributed. The product-focus of the respondents was strongest on integrated mechatronics $(27 \%)$, followed by software (25\%), integrated electronics and software (17\%) and mechanical components (13\%). 
Table 3: Overview of survey respondents

\begin{tabular}{lll}
\hline Categorization of respondents & Number valid responses & Percentage (rounded) \\
\hline by industry sector & $\mathbf{2 5 8}$ & $\mathbf{1 0 0 \%}$ \\
Defense & 69 & $27 \%$ \\
Government-sponsored aerospace & 33 & $13 \%$ \\
Commercial aerospace & 30 & $11 \%$ \\
Oil, gas and process industry & 18 & $7 \%$ \\
Other government-sponsored & 20 & $8 \%$ \\
Other (below 5\% each) & 88 & $34 \%$ \\
by total program new product development budget & $\mathbf{2 3 9}$ & $\mathbf{1 0 0 \%}$ \\
Less than \$1 million & 39 & $16 \%$ \\
\$1m - \$10m & 50 & $21 \%$ \\
\$10 - \$100m & 53 & $22 \%$ \\
\$100m - \$1 billion & 44 & $18 \%$ \\
More than \$1 billion & 30 & $13 \%$ \\
Did not know & 23 & $10 \%$ \\
by product type & $\mathbf{2 5 5}$ & $\mathbf{1 0 0 \%}$ \\
Mechanical: Components, materials, assemblies & 33 & $13 \%$ \\
Software & 64 & $25 \%$ \\
Integrated electronics and software & 35 & $14 \%$ \\
Integrated mechatronics (mechanical, electronics, software) & 69 & $27 \%$ \\
Service (consulting, process development) & 20 & $8 \%$ \\
Infrastructure or building & 13 & $5 \%$ \\
Other (below 5\% each) & 21 & $8 \%$ \\
\hline
\end{tabular}

\subsection{Statistical Methods of Data Analysis}

The responses collected using the survey generated a data set of categorical data with categories being binary (Yes, No) or ordinal data on ordered multi-level response scales such as the Likert scale (Strongly Disagree, Disagree, Neither Agree Nor Disagree, Agree, Strongly Agree). Two statistical methods were employed for the data analysis: Goodman and Kruskall's gamma (Agresti, 2010) was used to measure of association between the risk management practices and the outcome measures and between the outcome measures themselves. Correspondence Analysis (Greenacre, 2007) was used to visualize the responses to questions measuring risk management outcomes .

The Goodman-Kruskal Gamma analysis assumes that the response categories are ordered. The Gamma measure of association is a number between -1 and +1 that is analogous to the correlation coefficient for continuous data. The Gamma values are used to provide insight into potential causal relationships between risk management practices and measures of performance and insight into similarities within the measures of performance that can be used to cluster the survey questions into categories. As the dataset is based on 5-point ordinal scales, using the Gamma value is more appropriate 
than for example Spearman's Rho, as it is able to handle datasets that contain a relatively large number $(>10 \%)$ of ties in the rank-ordered data.

Correspondence Analysis is an exploratory data analysis method that provides graphical results that depict the vector of the responses to each question in a two-dimensional space (the first and second principal component). The distance in this two-dimensional space between each response and the origin is directly proportional to the chi-squared statistic used to evaluate the null hypothesis that the number of responses in each category for all the survey questions is independent of the survey question. The chi-squared test for independence has low statistical power and, because it does not assume that the response categories are ordered, it does not provide a measure of association between pairs of questions.

\section{$4 \quad$ Results}

\subsection{Clustering of measurements of risk management outcomes}

The survey included 22 questions in 3 groups that aimed at measuring the effectiveness of risk management outcomes (see Table 2, Section "Risk Management Performance", and Table 4). The 3 groups were: 1. Role and perception of risk management in the organization; 2. Quality of the program execution and 3. Overall program success (i.e. achievement of cost, schedule, technical and overall customer satisfaction targets).

To reduce the complexity of the analysis reported here, the outcome metrics were prioritized based on the findings. Nine of the 22 proposed outcome metrics were excluded in a first screening, as their Goodman-Kruskal Gamma values indicated a comparatively low association with the responses to the survey questions on risk management practices. This yielded a total of 13 outcome metrics (see Table 4). The cost target (D.1) and technical performance target (E.1) metrics were retained as important outcome metrics in the analysis, although they showed low association with risk management practices.

Based on the survey results, we performed a cluster analysis on the outcome metrics to either validate our original assumptions or define new valid categories to present the outcomes of risk management in new product development program environments. The outcome metrics were clustered using the complete-linkage hierarchical clustering method with one minus the absolute value of the Goodman-Kruskal Gamma as the measure of dissimilarity. Setting a clustering threshold to dissimilarity value of 0.4 (Goodman-Kruskal Gamma greater than 0.6 or less than -0.6), led to a re- 
distribution of the 13 outcome metrics. They do not fall into the original 3 groups that they were presented in during the survey (see above), but fall into 5 clusters: A: Making high-quality decisions in the program; B: Execute the program with a high level of stability; C: Create an Proactive, open organization; D: Execute the project successfully and E: Develop a successful product (also see Table 4 for an overview of the outcome metrics, the grouping they were originally presented in during the survey, and the clusters that resulted from the analysis described here). Figure 1 shows the dendrogram that results from applying complete-linkage hierarchical clustering to the measure of dissimilarity based on the GoodmanKruskal Gamma. Figure 2 shows the responses to the 13 outcome metrics as points in two-dimensional space of the first two principal components based on Correspondence Analysis results. It overlays the 5 clusters (A-E) derived from the Goodman-Kruskal Gamma statistical analysis using lines to join the data points that represents each of the metrics within a cluster. An interpretation of the data points and the lines that join the data points to form cluster A is as follows:

1. The data point for response A.1 indicates for the survey question, "Risk management results are important in decision making A.1," that the majority of the responses were Strongly Agree and the next most common response was Agree. There were very few responses of Disagree and Strongly Disagree and almost no responses of Neither Agree Nor Disagree.

2. The lines that join, A.1, A.2, and A.3 indicate that if a particular survey participant provided a response of Strongly Disagree to A.1, they are more likely to have provided a response of Strongly Disagree to A.2 and A.3.

3. The absence of lines joining A.1 to the data points for clusters B, C, D, and E indicate that the response of a survey participant to A.1 is likely to have no impact on their response to the survey questions represented by these clusters.

These 5 clusters and their outcome metrics are summarized in Table 4, including the shorthand notation used in Figure 2 and Figure 2 to identify the outcome metrics (e.g. A.1 for "Risk management results are important in decision making"). The table also includes an indication of the original grouping used in the survey. 
Table 4: Summary and Clusters of Outcome Metrics

\begin{tabular}{lll}
\hline Cluster & Outcome metric & Original grouping (1-3) in survey \\
\hline A & Quality Decision Making & \\
A.1 & Risk management results are important in decision making & 1 \\
A.2 & Risk management influences tradeoffs & 1 \\
A.3 & ROI of risk management was positive & 1 \\
B & High Program Stability & \\
B.1 & Stable execution and following defined processes & 2 \\
B.2 & Identified key risks and mitigated them & 2 \\
C & Proactive, open organization & \\
C.1 & Management was proactive in addressing risks and issues & 2 \\
C.2 & Concerns were heard and addressed & 2 \\
C.3 & OK to report "bad news" and concerns & 2 \\
C. 4 & Managers support risk management activities. & 1 \\
D & Project Success & \\
D.1 & Achieved cost target & 3 \\
D. 2 & Achieved schedule target & 3 \\
E & Product Success & \\
E.1 & Achieved technical performance target & 3 \\
E. 2 & Achieved overall customer satisfaction target & 3 \\
\hline
\end{tabular}

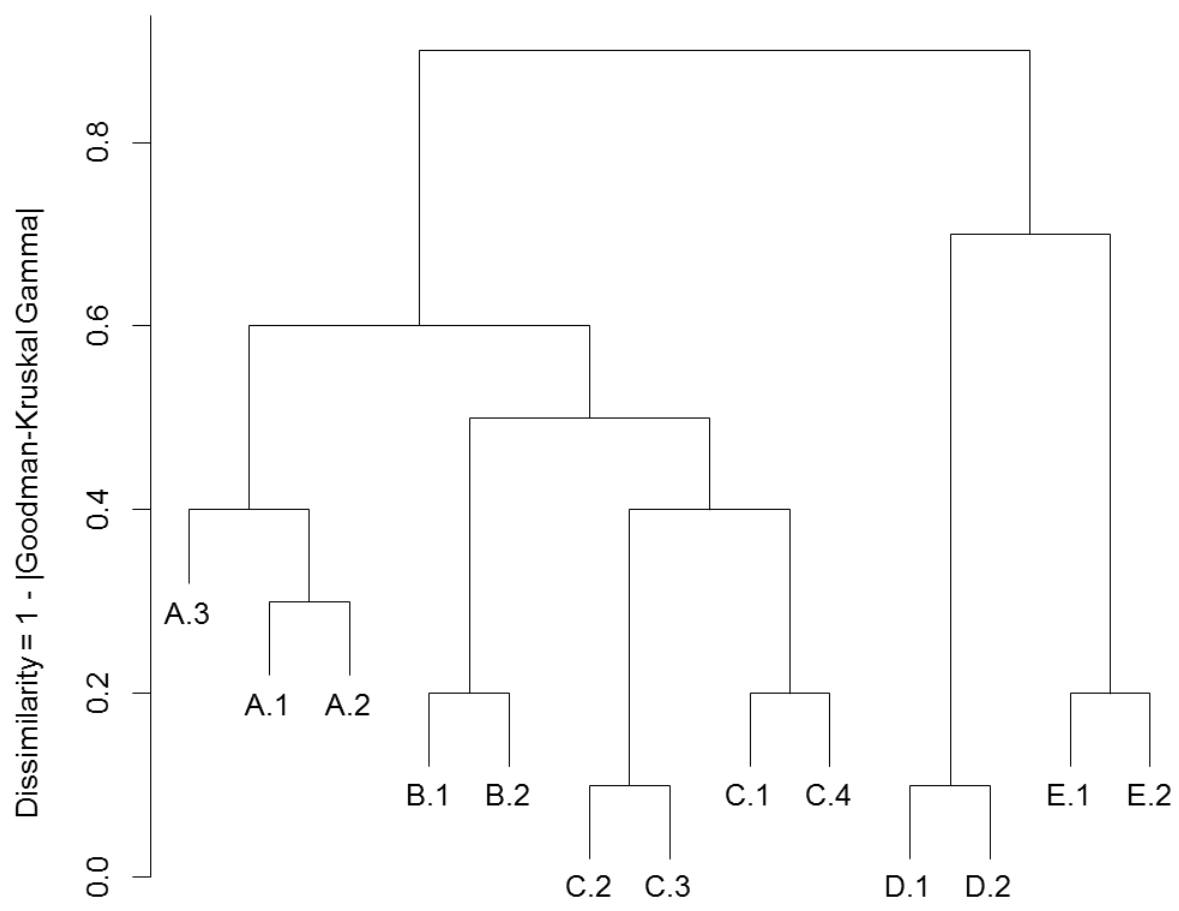

Figure 1: Dendrogram Showing Results of Clustering Based on Dissimilarity 


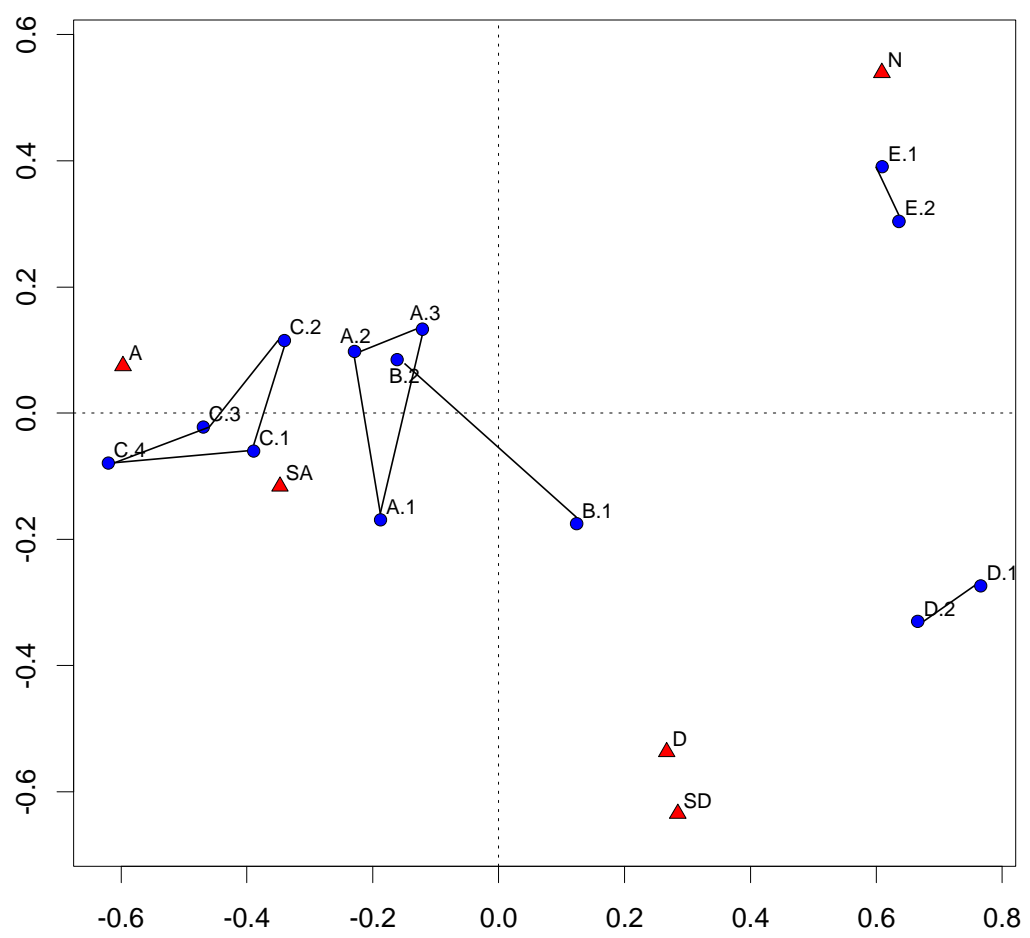

Figure 2: Visualization of Clustering of Outcome Metrics (Dissimilarity $=0.4$ )

\subsection{Association of risk management activities with program outcomes}

The survey included 95 questions on unique risk management practices (see Table 2 - all questions in the "Risk management practices" section except "Risks and their impact"). Associations were calculated between each of these 95 practices and the 13 outcome metrics, presented in Table 4. To select activities we consider as having an association with program outcomes, we identified risk management activities that have statistically significant $(\mathrm{p}<1 \%)$ associations greater than 0.4 with at least three of the 13 outcome metrics. This selection criterion allowed for activities that had a moderate level of association with outcomes and a moderate breadth of coverage across the set of outcomes.

These criteria resulted in the identification of 30 activities which we consider to have an association with program outcomes. For clarity of argument, we will present these 30 activities in six categories, as seen in Table 7 and Table 8 , and discussed in the following section. The six categories are: 1. Develop risk management skills and resources; 2. Tailor risk management to and integrate it with new product development; 3. Quantify the impact of risks on your main objectives; 4. Support all critical decisions with risk management results; 5. Monitor and review your risks, risk mitigation actions, and risk management process; and 6. Create transparency regarding new product development risks. The statistical results are summarized in Table 7 and Table 8. 


\section{Manuscript (Final Revision): Effect of Risk Management Practices}

A first attempt to categorize the 30 risk management activities along the ISO 31000 risk management process (see discussion in Section 2 and Table 1) did no yield satisfactory results. While some activities did easily fall within a risk management process step, others spanned categories. We therefore decided to categorize the 30 identified risk management activities more flexibly: Those that clearly aligned with a risk management process step were summarized in a corresponding category, and for those that did not, new categories were defined (see Table 5). Categories 3 (quantification) and 6 (transparency) align well with the analysis and identification process steps. Categories 1 (skills and resources) as well as 2 (tailoring) are not addressed by the risk management process as such. They speak to the overall design and development of the risk management process (aspects of which are covered for example by the "framework" for risk management process developed that is part of the ISO 31000 standard). Category 4 (support of decision making) unites elements of both risk evaluation and risk treatment, whereas category 5 (monitoring) addresses both the monitoring and review of risks and mitigation actions (part of the risk management process), as well as the review of the risk management process as such (which is again covered for example by the risk management process development framework of ISO 31000).

Table 5: Mapping of categories against risk management process steps

\begin{tabular}{|c|c|c|c|c|c|c|c|c|}
\hline & $\begin{array}{l}\text { Communication } \\
\text { and consultation }\end{array}$ & $\begin{array}{l}\text { Establishing } \\
\text { the context }\end{array}$ & $\begin{array}{l}\text { Risk } \\
\text { identification }\end{array}$ & $\begin{array}{l}\text { Risk } \\
\text { analysis }\end{array}$ & $\begin{array}{l}\text { Risk } \\
\text { evaluation }\end{array}$ & $\begin{array}{l}\text { Risk } \\
\text { treatment }\end{array}$ & $\begin{array}{l}\text { Monitoring } \\
\text { and Review }\end{array}$ & Other \\
\hline $\begin{array}{l}\text { 1. Develop risk management skills and } \\
\text { resources }\end{array}$ & & & & & & & & $\mathbf{X}$ \\
\hline $\begin{array}{l}\text { 2. Tailor risk management to and } \\
\text { integrate it with new product } \\
\text { development }\end{array}$ & & & & & & & & $\mathbf{X}$ \\
\hline $\begin{array}{l}\text { 3. Quantify the impact of risks on your } \\
\text { main objectives }\end{array}$ & & & & $\mathbf{X}$ & & & & \\
\hline $\begin{array}{l}\text { 4. Support all critical decisions with risk } \\
\text { management results }\end{array}$ & & & & & $\mathbf{X}$ & $\mathbf{X}$ & & \\
\hline $\begin{array}{l}\text { 5. Monitor and review your risks, risk } \\
\text { mitigation actions, and risk } \\
\text { management process }\end{array}$ & & & & & & & $\mathbf{X}$ & $\mathbf{X}$ \\
\hline $\begin{array}{l}\text { 6. Create transparency regarding new } \\
\text { product development risks }\end{array}$ & & & $\mathbf{X}$ & & & & & \\
\hline
\end{tabular}

\subsubsection{Develop risk management skills and resources}

Five risk management practices fall into this category:

1.1. Our employees are motivated to perform and implement risk management.

1.2. Our risk management has available, qualified experts to help implement the processes.

1.3. There are sufficient resources and personnel to conduct risk management. 


\section{Manuscript (Final Revision): Effect of Risk Management Practices}

1.4. Risk management teams are cross-functional and cross-organizational.

1.5. Our risk management takes human and cultural factors into account

The practices that have the widest association with new product development performance are numbers 1.1 and 1.4 , both associated with six outcome metrics, stressing the importance of motivation and cross-functional organization in risk management. The outcomes most heavily influenced are A.1, A.3, B.2 and C.1, highlighting the importance of skill and resources for the acceptance of risk management in the organization, as well as in establishing a proactive culture. Both practices 1.1 and 1.5 also have a positive association with achieving overall customer satisfaction targets in development.

While a high importance of skills and adequate resources are expected for the success of any project, these findings highlight their particular importance for risk management activities. The findings imply that NPD programs have to provide training for risk management, funding for and recognition of its activities. The cross-functional nature of NPD programs has to be reflected by cross-functional risk management teams. The risk management processes have to be adjusted to the particular human and cultural factors of each NPD program.

\subsubsection{Tailor risk management to and integrate it with new product development}

Again, there are five risk management practices in this category.

2.1. Our risk management is tailored to specific program/project needs.

2.2. We coordinate and integrate risk management activities of different functions and across the hierarchy.

2.3. Risk management is an integral part of all organizational processes

2.4. Risks and risk management activities are communicated to stakeholders (including management)

2.5. The risk management process is effectively integrated with other project/program management processes.

Practices 2.1 and 2.5 have the largest association with outcomes, being positively associated with 7 and 8 outcome metrics respectively, showing the importance of tailoring and integration of the risk management process. The largest influence is exerted on performance metrics across the board, i.e. A.1, A.2, B.2, and C.1. The effective integration of risk management practices into the project management processes (2.5) also influences the overall customer satisfaction (E.2). 


\section{Manuscript (Final Revision): Effect of Risk Management Practices}

Most project management and risk management tools and techniques are generic in nature (Raz et al., 2002). However NPD projects differ in size, complexity, technology maturity, constraints, objectives and other dimensions. Our findings support the notion that there is a need to tailor and adapt risk management practice to the specific needs and characteristics of a particular NPD project. The findings imply that the practice of "one size fits all" is inadequate. In particular, NPD program managers must integrate the risk management practices to the particular NPD program objectives, use it to bridge functions and hierarchies in the program, and reach all relevant stakeholder groups.

\subsubsection{Quantify the impact of risks on your main objectives}

The five risk management practices in this category are:

3.1. The impacts of risks are quantified using cost as a dimension.

3.2. The impacts of risks are quantified using technical performance or quality as a dimension.

3.3. The impacts of risks are quantified using schedule as a dimension.

3.4. Assessment of risk on scales, e.g. 1-5 scale for probability and impact.

3.5. Before they are implemented, risk mitigation actions are evaluated based on the reduction of impact of risk through the mitigation action.

Practice 3.2, addressing the need for quantifying technical risks, has the broadest association with outcome metrics with a total of 8 metrics being associated. All five practices have a positive association with B.2 (successful identification and mitigation of key risks), while four practices support C.1 (proactive management). Practices 3.1 and 3.2 had a positive association with D.2, successfully achieving the overall project schedule targets.

From a managerial point of view, these findings emphasize the need to quantify risks along the core dimensions of NPD program objectives, such as cost, performance and schedule. It argues in favor of a multi-dimensional assessment of risks. A semi-quantitative assessment on ranked scales seems to be sufficient (as opposed to a detailed quantification based on sophisticated models). The findings also highlight the important relationship between risk quantification and quantifying the risk-reduction impact of mitigation actions. 


\subsubsection{Support all critical decisions with risk management results}

Three risk management practices fall in this category:

4.1. Resources are allocated to reduce largest risks as early as possible.

4.2. Forecasts and projections (e.g. cost, schedule, performance) are adjusted based on risk assessment.

4.3. The results of the risk analysis are considered in making technical, schedule and/or cost trade-offs.

Practices 4.1 and 4.3 each influence a wide range of outcome metrics, eight in total. The outcome metrics that are positively influenced by all three risk management practices are A.2, B.2, C.1, and C.4. Practice 4.1 (reducing largest risks first) also has a positive association with achieving overall customer satisfaction (E.2).

These findings underscore the practical importance of risk management findings in managerial and technical decision making processes. The findings emphasize that NPD programs must face significant risks decisively in the early phases of the program, and not succumb to the urge of burying them in technical and organizational complexities to avoid difficult decisions. Also during the early program phases, risk management results should be used to inform trade-off studies to arrive at a robust architecture that takes the known risks into account. And when risk management informs forecasts and projections, it supports the program manager in setting realistic plans and expectations that are robust against program risks and provide the minimum reasonable amount of buffers at the appropriate points.

\subsubsection{Monitor and review your risks, risk mitigation actions, and risk management process}

A total of nine risk management practices are summarized in this category:

5.1. Risks were escalated to senior management according to guidelines.

5.2. Risks were regularly re-assessed according to guidelines, e.g. after specific events or after a certain time interval.

5.3. The risk management process was regularly reviewed and improved

5.4. A formal feedback system was used to monitor the execution of risk mitigation actions

5.5. An early warning system was used to track critical risks and decide on activating mitigation measures.

5.6. Risk mitigation plans are monitored. 
5.7. Tracking of error/issue/failure rates is used as a key performance indicator to track risks.

5.8. Our risk management is dynamic, iterative and responsive to change.

5.9. Our risk management is systematic, structured and timely.

Notably, practices 5.8 and 5.9 have a positive association with 10 out of the 13 outcome metrics - the largest in the survey. Practices 5.3 and 5.6 address nine and eight outcome metrics, respectively. The outcome metrics A.1 and C.4 were positively influenced by all practices in the category, while B.2 and C.1 were still influenced by eight practices. This highlights the importance for continuous monitoring and adaptation to achieve acceptance and impact through risk management in the development programs. Practices 5.8 and 5.9 also have a positive influence on overall customer satisfaction (E.2).

This large group of risk management practices underscore the importance of risk management practices being frequently (if not continuously) executed throughout the NPD program, as opposed to sporadic bursts of activities at major milestones. It highlights that monitoring and review covers many facets: It addresses risks, suggesting that their assessment, as well as their predictive and reactive escalation through the decision making hierarchy, must be kept current. At the same time, the impact of unmitigated risks can be tracked and used as a indicator for the quality of the risk management process. The findings speak to the mitigation actions and that the planning of mitigation actions as well as their execution, suggesting that those activities be merged with the tracking of other NPD program management and improvement activities. Finally, related to the notion of tailoring and integration discussed above, the risk management process as such must be assessed and where needed, improved and adapted to the current needs.

\subsubsection{Create transparency regarding new product development risks.}

Three risk management practices fall into this category:

6.1. Our risk management is based on the best available information.

6.2. Our risk management is transparent and inclusive towards all stakeholders.

6.3. Our risk management explicitly addresses uncertainty. 


\section{Manuscript (Final Revision): Effect of Risk Management Practices}

Practices 6.1 and 6.2 both influence 9 outcome metrics, while practice 6.3 influences 5 outcome metrics. The outcome metrics A.1, B.1, B.2, and C.1 are positively influenced by all 3 practices. Practices 6.2 and 6.3 also have a positive influence on overall customer satisfaction (E.2).

These findings suggest that in order to be an effective management tool, risk management practices must create transparency for decision makers in the often complex world of NPD programs. In particular, it is important that risk management activities are based on current information and where necessary, latest estimates and expert opinions. In order to ensure not only coverage of all possible risks, but also the coverage of those risks from all relevant angles, risk management activities benefit from the inclusion of all relevant stakeholders. Finally, risk management can and should be used to explicitly describe, quantify and manage uncertainty in a NPD program, instead of ignoring it (and hoping for the best), or addressing it implicitly hidden buffers and margins, preventing open discussion and resolution of risks.

\subsection{New product development program outcomes that can be influenced by risk management activities}

Based on the risk management practices presented in Table 7 and Table 8 and discussed above, we counted the number of risk management practices that influenced each of the outcome metrics. This provides an indication of the outcome metrics which are most readily influenced by risk management activities. These results are summarized in Table 6 .

The outcome metrics that are associated with the largest number of risk management practices presented in this paper are

- $\quad$ the successful identification and mitigation of key risks (B.2, by 24 of the practices),

- $\quad$ making risk management results relevant for decision making (A.1, by 23 practices),

- $\quad$ supporting a proactive management style in the project environment (C.1, also by 23 practices),

- $\quad$ increasing the support for risk management activities by senior managers (C.4, by 21 practices)

- $\quad$ making better trade-off decisions in the development project (A.2, by 18 practices); and

- Improving the return-on-investment of risk management activities (A.3, by 16 practices)

These findings suggest that improved decision making processes is one of the major contributions that risk management makes to NPD programs. It could be argued that this has positive implications for the second area, creating a proactive 
and supportive management environment in the NPD program, ultimately allowing managers to better identify and retire key risks.

Generally, we assume that the intermediary outcome metrics (A: quality decision making, B: high program stability, and C: open problem-solving organization) contribute to project (D) and product (E) success. While our current analysis of the data does not show a large number of direct associations between risk management process and final program outcomes (i.e., project and product success), the existing literature supports this assumption. For example, regarding quality decision making (A), Krishnan and Ulrich (2001) present an extensive review of the product development literature from a decision-making perspective, suggesting the important role of decision-making throughout the product development process. Bourgeois and Eisenhardt (1988) explored strategic decision making and found that better performing firms follow higher quality decision methods. Strategies for achieving program stability (B) have been explored in depth by the project scheduling community, for example through the use of buffers (Van de Vonder et al., 2005). Program stability has been proven to be perceived by managers to be as important as cost, schedule and performance measures (Swartz, 2008). In exploring the role of problem-solving on product development (C), Wheelwright and Clark (1994) conclude that effective problem solving is "a critical and necessary part of an outstanding development process". Additionally the positive impact of open communication in product development is presented by Griffin and Hauser (1992), and references therein.

To investigate these indirect associations, we conducted an analysis of partial associations of the project and product success outcome metrics (D.x and E.x) with risk management practices, i.e. the indirect associations of risk management practices to overall success (D.x and E.x) via intermediate outcome metrics (clusters A.x-C.x). Using the method of partial associations with fixed intermediate variables (Graybill, 1976, p. 115; Yule, 1907), our preliminary results suggest a high number of significant (Gamma > 0.4) positive partial associations (see Table 9 for details):

- D.1 Achieved cost target: 25 risk management practices

- D.2 Achieved schedule target: 18 risk management practices

- E.1 Achieved technical performance target: 17 risk management practices

- E.2 Achieved overall customer satisfaction target: 28 risk management practices 


\section{Manuscript (Final Revision): Effect of Risk Management Practices}

These results indicate that while risk management practices may only have a relatively weak direct influence on project and product success, they do indirectly influence project and product success significantly through improved decision making (A.x), program stability and a proactive (B.x), open organization (C.x).

Table 6: Number of risk management activities (from a total of 30) positively associated with the 13 outcome metrics.

\begin{tabular}{lll}
\hline Outcome metric & \multicolumn{2}{c}{ associated risk management practices } \\
& $\#$ & $\%$ \\
\hline A Quality Decision Making & & $77 \%$ \\
A.1 Risk management results important in decision making & 23 & $60 \%$ \\
A.2 Risk management influences tradeoffs & 18 & $53 \%$ \\
A.3 ROI of risk management was positive & 16 & \\
B High Program Stability & 7 & $23 \%$ \\
B.1 Stable execution and following defined processes & 24 & $80 \%$ \\
B.2 Identified key risks and mitigated them & & $77 \%$ \\
C Proactive, open organization & 23 & $37 \%$ \\
C.1 Management was proactive in addressing risks and issues & 11 & $37 \%$ \\
C.2 Concerns were heard and addressed & 11 & $70 \%$ \\
C.3 OK to report "bad news" and concerns & 21 & \\
C.4 Managers support risk management activities. & & $0 \%$ \\
D Project Success & 0 & $7 \%$ \\
D.1 Achieved cost target & 2 & $0 \%$ \\
D.2 Achieved schedule target & & $27 \%$ \\
E Product Success & 0 & 8 \\
E.1 Achieved technical performance target & & \\
E.2 Achieved overall customer satisfaction target & & \\
\hline
\end{tabular}

\section{Discussion}

\subsection{Results}

In this paper, we investigated the relationship between specific risk management practices and five new product development project outcome metrics: A. Quality Decision Making, B. High Program Stability, C. Proactive, open organization, D. Project Success and E. Product Success. Most notably, we were able to show that the specific risk management practices discussed in this paper have a positive association with the first three categories of outcome metrics (decision making, stability and problem-solving), as well as 10 practices having a positive association with Project Success (2) and Product Success (8). From the four top-level success metrics (achieving cost, schedule, technical, and customer satisfaction targets), customer satisfaction was influenced by eight practices, whereas schedule was influenced by only two practices. No practices were identified to be associated directly with either cost or technical performance. As discussed in the introduction to this paper, Wirthlin (2009) concluded that flexibility, transparency, and quality are the most valued in new product development programs and are essentially non-negotiable, whereas cost and schedule are 


\section{Manuscript (Final Revision): Effect of Risk Management Practices}

negotiable. Our measures of proactive, open organization are related to Wirthlin's measures of transparency and flexibility, and our measure of overall satisfaction is related to Wirthlin's measure of quality. Our research supports the assertion that risk management activities on engineering programs are consistent with treating the overall objectives of flexibility, transparency, and quality as non-negotiable while allowing cost and schedule objectives to be treated as negotiable. Additionally, the findings discussed in Section 4.3 point towards significant indirect associations between risk management practices and project (D.x) and product success (E.x) via the intermediate success variables (A.x: quality decision making, B.x: high program stability and C.x: open, proactive organization).

There are several managerial implications for risk managers as well as managers of new product development projects that can be drawn from this paper: First, measuring risk management success by overall project and product success does not seem to be adequate, although prior research has shown the positive contribution risk management makes. Rather, based on the results of this paper, we suggest defining top-level risk management performance metrics as: 1 . Improvement of decision making in the project; 2. Stability with which the project is being executed, and 3. Problem-solving capabilities of the project and organization. The sub-metrics we used in our research and presented in this paper can be considered as a starting point for defining these metrics in more detail. Second, we have shown that certain risk management practices have a positive association with our three proposed top-level risk management performance metrics, as well as on overall customer satisfaction and schedule adherence. The results suggest that risk managers and new product development project managers should place particular attention on implementing these practices. They fall into six categories: 1. Develop risk management skills and resources; 2. Tailor risk management to and integrate it with new product development; 3. Quantify impacts of risks on your main objectives; 4. Support all critical decisions with risk management results; 5. Monitor and review your risks, risk mitigation actions, and risk management process; and 6. Create transparency regarding new product development risks.

In particular, categories 2 and 5 highlight the need to critically reflect and analyze existing risk management standards before implementing them in a "one size fits all" mentality in one's organization or project. While our findings do not necessarily contradict existing risk management standards, they highlight the need for any organization to continuously reflect on the value that risk management adds to their product development activities and continuously adapt risk management processes and organizations based on their specific needs and experience. 
Regarding the relatively new ISO 31000 standard, it is noteworthy that 8 out of the 11 so called "risk management principles" put forth are included in the risk management practices identified in this paper as having positive association with NPD outcome measures. The ISO 31000 also includes specific recommendations on customization of the risk management process during first implementation, as well as detailed up-front adaptation to the specific stakeholder needs. Overall, it seems well aligned with the findings of this paper.

\subsection{Limitations and Opportunities for Future Research}

This paper has several limitations, which present opportunities for future research:

The paper does not explore the difference in perception between different sub-groups of respondents, in particular between program managers and risk managers, nor does it explore other possible intervening variables. Preliminary results show minor differences between these two groups in the measured associations of risk management practices with performance measures. Other candidates for intervening variables, for example government vs industry respondents, or respondents from small vs respondents from large organizations, also remain unexplored. This detailed analysis is beyond the scope and length of this paper and will be addressed in our future research.

As noted in Table 2, due to the two-step method of data collection, there are a varying number of respondents for different sub-sections of risk management practices in the survey. This may have contributed to lower significance scores for those risk management practices where fewer responses were collected. However, as the number of respondents in each section is still high (over 100), we expect this effect to be relatively small.

The research results presented in this paper represent a cross-sectional study that explores the association between risk management practices and NPD program outcomes. While we provide empirical proof for the existence and strength of those associations, statistical measures of association or correlation do not, by their nature, imply causality. While we interpret our findings in line with the pertinent literature (see our discussion in Sections 1 and 2) as risk management practices positively influencing the performance of NPD programs, the reverse may also be argued for (for example that a NPD program running stable supports better execution of risk management activities). Future research should be targeted at the specific mechanisms by which risk management practices influence NPD program performance, for example by indepth action research or detailed case studies describing those mechanisms. 


\section{Manuscript (Final Revision): Effect of Risk Management Practices}

Some existing effective risk management practices may not have been considered in the survey, because they are not discussed in the literature, we failed to identify relevant literature, or because they were excluded during the testing phase as not effective by the subject matter experts group.

\section{Acknowledgements}

The authors thank the King Fahd University of Petroleum and Minerals in Dhahran, Saudi Arabia, for funding the research reported in this paper through the Center for Clean Water and Clean Energy at MIT and KFUPM through project R11-DMN-09. The authors gratefully acknowledge further funding support through the Lean Advancement Initiative at MIT and the MIT-SUTD International Design Center. We are also grateful to all survey respondents, as well as to the members of our industry focus group, benchmarking partners, professional organizations and academic partners that helped us develop, test and disseminate the survey, most notably at the Air Force Institute of Technology, Futron, INCOSE, NDIA and RiskSIG. 
Manuscript (Final Revision): Effect of Risk Management Practices

Table 7: Goodman-Kruskal Gamma associations between outcome metrics and risk management activities (Part 1/2)

\begin{tabular}{|c|c|c|c|c|c|c|c|c|c|c|c|c|c|}
\hline & \multicolumn{3}{|c|}{$\begin{array}{c}\text { A. Quality } \\
\text { Decision Making }\end{array}$} & \multicolumn{2}{|c|}{$\begin{array}{l}\text { B. High } \\
\text { Program } \\
\text { Stability }\end{array}$} & \multicolumn{4}{|c|}{$\begin{array}{c}\text { C. } \\
\text { Proactive, open } \\
\text { organization }\end{array}$} & \multicolumn{2}{|c|}{$\begin{array}{l}\text { D. Project } \\
\text { Success }\end{array}$} & \multicolumn{2}{|c|}{$\begin{array}{l}\text { E. Product } \\
\text { Success }\end{array}$} \\
\hline & A.1 & A. 2 & A.3 & B.1 & B.2 & C.1 & C. 2 & C. 3 & C. 4 & D.1 & D.2 & E.1 & E. 2 \\
\hline \multicolumn{14}{|c|}{ 1. DEVELOP RISK MANAGEMENT SKILLS AND RESOURCES } \\
\hline $\begin{array}{l}\text { 1.1 Our employees are motivated to } \\
\text { perform/implement RM. }\end{array}$ & 0.49 & & 0.44 & & 0.47 & 0.47 & & & 0.55 & & & & 0.43 \\
\hline $\begin{array}{l}1.2 \text { Our RM has available, qualified } \\
\text { experts to help implement the } \\
\text { processes. }\end{array}$ & 0.56 & & 0.43 & & 0.47 & 0.48 & & & 0.43 & & & & \\
\hline $\begin{array}{l}\text { 1.3 There are sufficient resources and } \\
\text { personnel to conduct RM. }\end{array}$ & 0.57 & & 0.46 & & 0.47 & 0.50 & & & & & & & \\
\hline $\begin{array}{l}\text { 1.4 RM teams are cross-functional and } \\
\text { cross-organizational. }\end{array}$ & 0.49 & 0.47 & 0.47 & & & 0.53 & 0.44 & & 0.51 & & & & \\
\hline $\begin{array}{l}\text { 1.5 Our RM takes human and cultural } \\
\text { factors into account }\end{array}$ & 0.49 & & & & 0.46 & & & & & & & & 0.41 \\
\hline \multicolumn{14}{|c|}{$\begin{array}{l}\text { 2. TAILOR RISK MANAGEMENT TO AND INTEGRATE IT WITH NEW PRODUCT } \\
\text { DEVELOPMENT }\end{array}$} \\
\hline $\begin{array}{l}2.1 \text { Our RM is tailored to specific } \\
\text { program/project needs. }\end{array}$ & 0.57 & 0.52 & 0.40 & & 0.53 & 0.53 & 0.45 & 0.45 & & & & & \\
\hline $\begin{array}{l}2.2 \text { We coordinate and integrate RM } \\
\text { activities of different functions and } \\
\text { across the hierarchy. }\end{array}$ & 0.48 & 0.43 & 0.46 & & 0.43 & 0.58 & 0.40 & & & & & & \\
\hline $\begin{array}{l}2.3 \mathrm{RM} \text { is an integral part of all } \\
\text { organizational processes }\end{array}$ & 0.49 & 0.42 & & & 0.42 & & & & 0.42 & & & & \\
\hline $\begin{array}{l}\text { 2.4 Risks and RM activities are } \\
\text { communicated to stakeholders } \\
\text { (including management) }\end{array}$ & & & 0.41 & 0.48 & & 0.54 & & & 0.50 & & & & \\
\hline $\begin{array}{l}2.5 \text { The RM process is effectively } \\
\text { integrated with other project/program } \\
\text { management processes. }\end{array}$ & 0.50 & 0.46 & & & 0.53 & 0.48 & 0.42 & 0.45 & 0.53 & & & & 0.46 \\
\hline \multicolumn{14}{|c|}{ 3. QUANTIFY IMPACT OF RISKS ON YOUR MAIN OBJECTIVES } \\
\hline $\begin{array}{l}3.1 \text { The impacts of risks are quantified } \\
\text { using cost as a dimension. }\end{array}$ & 0.43 & 0.48 & & & 0.47 & 0.49 & & & & & 0.41 & & \\
\hline $\begin{array}{l}3.2 \text { The impacts of risks are quantified } \\
\text { using technical performance or quality } \\
\text { as a dimension. }\end{array}$ & 0.55 & 0.45 & & & 0.63 & 0.69 & 0.56 & 0.64 & 0.76 & & 0.49 & & \\
\hline $\begin{array}{l}3.3 \text { The impacts of risks are quantified } \\
\text { using schedule as a dimension. }\end{array}$ & & & & & 0.47 & 0.43 & & & 0.40 & & & & \\
\hline $\begin{array}{l}\text { 3.4 Assessment of risk on scales, e.g. } 1 \text { - } \\
5 \text { scale for probability and impact. }\end{array}$ & 0.43 & 0.42 & 0.52 & & 0.40 & 0.57 & & & & & & & \\
\hline $\begin{array}{l}3.5 \text { Before they are implemented, risk } \\
\text { mitigation actions are evaluated based } \\
\text { on the reduction of impact of risk } \\
\text { through the mitigation action. }\end{array}$ & & & & 0.45 & 0.41 & & 0.51 & & 0.41 & & & & \\
\hline
\end{tabular}


Manuscript (Final Revision): Effect of Risk Management Practices

Table 8: Goodman-Kruskal Gamma associations between outcome metrics and risk management activities (Part 2/2)

\begin{tabular}{|c|c|c|c|c|c|c|c|c|c|c|c|c|c|}
\hline & \multicolumn{3}{|c|}{$\begin{array}{c}\text { A. Quality } \\
\text { Decision Making }\end{array}$} & \multicolumn{2}{|c|}{$\begin{array}{l}\text { B. High } \\
\text { Program } \\
\text { Stability }\end{array}$} & \multicolumn{4}{|c|}{$\begin{array}{l}\text { C. } \\
\text { Proactive, open } \\
\text { organization }\end{array}$} & \multicolumn{2}{|c|}{$\begin{array}{l}\text { D. } \\
\text { Successful } \\
\text { Project }\end{array}$} & \multicolumn{2}{|c|}{$\begin{array}{l}\text { E. } \\
\text { Successful } \\
\text { Product }\end{array}$} \\
\hline & A.1 & A.2 & A.3 & B.1 & B.2 & C.1 & C. 2 & C. 3 & C. 4 & D.1 & D.2 & E.1 & E.2 \\
\hline & \multicolumn{13}{|c|}{ 4. SUPPORT ALL CRITICAL DECISIONS WITH RISK MANAGEMENT RESULTS } \\
\hline $\begin{array}{l}4.1 \text { Resources are allocated to reduce } \\
\text { largest risks as early as possible. }\end{array}$ & & 0.56 & 0.53 & & 0.50 & 0.58 & 0.52 & 0.49 & 0.48 & & & & 0.42 \\
\hline $\begin{array}{l}\text { 4.2 Forecasts and projections (e.g. cost, } \\
\text { schedule, performance) are adjusted } \\
\text { based on risk assessment. }\end{array}$ & 0.40 & 0.48 & & & 0.45 & 0.44 & & & 0.50 & & & & \\
\hline $\begin{array}{l}4.3 \text { The results of the risk analysis are } \\
\text { considered in making technical, } \\
\text { schedule and/or cost trade-offs. }\end{array}$ & 0.47 & 0.69 & 0.54 & & 0.47 & 0.60 & 0.48 & 0.44 & 0.52 & & & & \\
\hline & \multicolumn{13}{|c|}{$\begin{array}{l}\text { 5. MONITOR AND REVIEW YOUR RISKS, RISK MITIGATION ACTIONS, AND RM } \\
\text { PROCESS }\end{array}$} \\
\hline $\begin{array}{l}\text { 5.1 Risks were escalated to senior } \\
\text { management according to guidelines. }\end{array}$ & 0.65 & 0.53 & 0.48 & 0.48 & 0.52 & 0.72 & & & 0.43 & & & & \\
\hline $\begin{array}{l}\text { 5.2 Risks were regularly re-assessed } \\
\text { according to guidelines, e.g. after } \\
\text { specific events or after a certain time } \\
\text { interval. }\end{array}$ & 0.61 & 0.57 & 0.47 & & 0.52 & 0.63 & & 0.45 & 0.53 & & & & \\
\hline $\begin{array}{l}5.3 \text { The risk management process was } \\
\text { regularly reviewed and improved }\end{array}$ & 0.63 & 0.53 & 0.61 & 0.48 & 0.53 & 0.61 & 0.40 & 0.49 & 0.46 & & & & \\
\hline $\begin{array}{l}5.4 \text { A formal feedback system was used } \\
\text { to monitor the execution of risk } \\
\text { mitigation actions }\end{array}$ & 0.62 & & & & 0.45 & 0.64 & & 0.44 & 0.61 & & & & \\
\hline $\begin{array}{l}5.5 \text { An early warning system was used } \\
\text { to track critical risks and decide on } \\
\text { activating mitigation measures. }\end{array}$ & 0.44 & & & & 0.41 & 0.63 & & & 0.55 & & & & \\
\hline $\begin{array}{l}\text { 5.6 Risk mitigation plans are used for } \\
\text { monitoring. }\end{array}$ & 0.65 & 0.68 & 0.63 & 0.41 & 0.55 & 0.55 & & 0.48 & 0.63 & & & & \\
\hline $\begin{array}{l}5.7 \text { Tracking of error/issue/failure rates } \\
\text { is used as a key performance indicator } \\
\text { to track risks. }\end{array}$ & 0.43 & 0.44 & & & & & & & 0.55 & & & & \\
\hline $\begin{array}{l}5.8 \text { Our RM is dynamic, iterative and } \\
\text { responsive to change. }\end{array}$ & 0.54 & 0.52 & 0.55 & 0.51 & 0.62 & 0.63 & 0.62 & 0.51 & 0.41 & & & & 0.40 \\
\hline $\begin{array}{l}5.9 \text { Our RM is systematic, structured } \\
\text { and timely. }\end{array}$ & 0.68 & 0.57 & 0.55 & 0.58 & 0.65 & 0.65 & 0.50 & 0.48 & 0.54 & & & & 0.42 \\
\hline \multicolumn{14}{|c|}{ 6. CREATE TRANSPARENCY REGARDING NEW PRODUCT DEVELOPMENT RISKS } \\
\hline $\begin{array}{l}\text { 6.1 Our RM is based on the best } \\
\text { available information. }\end{array}$ & 0.53 & 0.53 & 0.46 & 0.51 & 0.52 & 0.68 & 0.49 & 0.47 & 0.61 & & & & \\
\hline $\begin{array}{l}\text { 6.2 Our RM is transparent and } \\
\text { inclusive towards all stakeholders. }\end{array}$ & 0.63 & 0.64 & 0.48 & 0.57 & 0.55 & 0.55 & 0.52 & 0.62 & & & & & 0.51 \\
\hline $\begin{array}{l}\text { 6.3 Our RM explicitly addresses } \\
\text { uncertainty. }\end{array}$ & 0.47 & & & 0.43 & 0.45 & 0.56 & & & & & & & 0.42 \\
\hline
\end{tabular}


Table 9: Partial associations with fixed intermediary variables (outcome measures A.x-C.x) of risk management practices with project (D.x) and product success (E.x) measures (Gamma $>0.4)$

\begin{tabular}{|c|c|c|c|c|}
\hline & \multicolumn{2}{|c|}{$\begin{array}{c}\text { D. } \\
\text { Successful } \\
\text { Project }\end{array}$} & \multicolumn{2}{|c|}{$\begin{array}{c}\text { E. } \\
\text { Successful } \\
\text { Product }\end{array}$} \\
\hline & D. 1 & D.2 & E.1 & E.2 \\
\hline \multicolumn{5}{|l|}{ 1. DEVELOP RISK MANAGEMENT SKILLS AND RESOURCES } \\
\hline 1.1 Our employees are motivated to perform/implement RM. & 0.58 & 0.58 & & 0.54 \\
\hline 1.2 Our RM has available, qualified experts to help implement the processes. & 0.43 & & & 0.50 \\
\hline 1.3 There are sufficient resources and personnel to conduct RM. & 0.41 & & 0.40 & 0.55 \\
\hline 1.4 RM teams are cross-functional and cross-organizational. & 0.46 & & & 0.40 \\
\hline 1.5 Our RM takes human and cultural factors into account & 0.59 & 0.48 & 0.49 & 0.67 \\
\hline \multicolumn{5}{|c|}{ 2. TAILOR RISK MANAGEMENT TO AND INTEGRATE IT WITH NEW PRODUCT DEVELOPMENT } \\
\hline 2.1 Our RM is tailored to specific program/project needs. & 0.56 & 0.42 & 0.56 & 0.76 \\
\hline 2.2 We coordinate and integrate RM activities of different functions and across the hierarchy. & 0.56 & & 0.62 & 0.71 \\
\hline $2.3 \mathrm{RM}$ is an integral part of all organizational processes & 0.64 & 0.60 & & 0.54 \\
\hline 2.4 Risks and RM activities are communicated to stakeholders (including management) & 0.62 & & 0.46 & 0.46 \\
\hline 2.5 The RM process is effectively integrated with other project/program management processes. & 0.70 & 0.66 & & 0.70 \\
\hline \multicolumn{5}{|l|}{$\begin{array}{l}\text { 3. QUANTIFY IMPACT OF RISKS ON YOUR MAIN OBJECTIVES } \\
\end{array}$} \\
\hline 3.1 The impacts of risks are quantified using cost as a dimension. & & & 0.43 & 0.63 \\
\hline 3.2 The impacts of risks are quantified using technical performance or quality as a dimension. & 0.55 & 0.62 & & 0.72 \\
\hline 3.3 The impacts of risks are quantified using schedule as a dimension. & & 0.45 & & 0.69 \\
\hline 3.4 Assessment of risk on scales, e.g. 1-5 scale for probability and impact. & & & 0.44 & 0.58 \\
\hline $\begin{array}{l}3.5 \text { Before they are implemented, risk mitigation actions are evaluated based on the reduction of impact } \\
\text { of risk through the mitigation action. }\end{array}$ & 0.44 & & & \\
\hline \multicolumn{5}{|l|}{$\begin{array}{l}\text { 4. SUPPORT ALL CRITICAL DECISIONS WITH RISK MANAGEMENT RESULTS } \\
\end{array}$} \\
\hline 4.1 Resources are allocated to reduce largest risks as early as possible. & 0.62 & 0.47 & & 0.66 \\
\hline 4.2 Forecasts and projections (e.g. cost, schedule, performance) are adjusted based on risk assessment. & 0.57 & 0.55 & & 0.57 \\
\hline 4.3 The results of the risk analysis are considered in making technical, schedule and/or cost trade-offs. & 0.45 & & & 0.48 \\
\hline \multicolumn{5}{|c|}{ 5. MONITOR AND REVIEW YOUR RISKS, RISK MITIGATION ACTIONS, AND RM PROCESS } \\
\hline 5.1 Risks were escalated to senior management according to guidelines. & & & 0.70 & 0.54 \\
\hline $\begin{array}{l}5.2 \text { Risks were regularly re-assessed according to guidelines, e.g. after specific events or after a certain } \\
\text { time interval. }\end{array}$ & 0.56 & 0.48 & 0.43 & 0.72 \\
\hline 5.3 The risk management process was regularly reviewed and improved & 0.69 & 0.53 & 0.51 & 0.72 \\
\hline 5.4 A formal feedback system was used to monitor the execution of risk mitigation actions & 0.56 & 0.46 & 0.47 & 0.65 \\
\hline $\begin{array}{l}\text { 5.5 An early warning system was used to track critical risks and decide on activating mitigation } \\
\text { measures. }\end{array}$ & 0.47 & 0.42 & 0.42 & 0.65 \\
\hline 5.6 Risk mitigation plans are used for monitoring. & 0.62 & 0.59 & & 0.51 \\
\hline \multicolumn{5}{|l|}{ 5.7 Tracking of error/issue/failure rates is used as a key performance indicator to track risks. } \\
\hline 5.8 Our RM is dynamic, iterative and responsive to change. & 0.60 & & 0.56 & 0.70 \\
\hline 5.9 Our RM is systematic, structured and timely. & 0.67 & 0.49 & 0.53 & 0.67 \\
\hline \multicolumn{5}{|l|}{$\begin{array}{l}\text { 6. CREATE TRANSPARENCY REGARDING NEW PRODUCT DEVELOPMENT RISKS } \\
\end{array}$} \\
\hline 6.1 Our RM is based on the best available information. & 0.62 & 0.40 & 0.52 & 0.61 \\
\hline 6.2 Our RM is transparent and inclusive towards all stakeholders. & 0.71 & 0.51 & 0.56 & 0.72 \\
\hline 6.3 Our RM explicitly addresses uncertainty. & 0.63 & 0.43 & 0.79 & 0.78 \\
\hline
\end{tabular}




\section{$7 \quad$ References}

Agresti, A., 2010. Analysis of Ordinal Categorical Data, 2nd ed. Wiley, Hudson, NJ.

Ahmad, S., Mallick, D.N., Schroeder, R.G., 2013. New Product Development: Impact of Project Characteristics and Development Practices on Performance. J. Prod. Innov. Manag. 30, 331-348.

Baba, Y., Kikuchi, J., Mori, S., 1995. Japan's R\&D strategy reconsidered: Departure from the manageable risks. Technovation 15, 65-78.

Bassler, D., Oehmen, J., Seering, W., Ben-Daya, M., 2011. A comparison of the integration of risk management principles in product development, in: Culley, S.J., Hicks, B.J., McAloone, T.C., Howard, T.J., Cantemessa, M. (Eds.), Proceedings of the 18th International Conference on Engineering Design (ICED11), Vol. 3. Lyngby/Copenhagen, Denmark, pp. 306-316.

Bourgeois, L.J., Eisenhardt, K.M., 1988. Strategic Decision Processes in High Velocity Environments: Four Cases in the Microcomputer Industry. Manage. Sci. 34, 816-835.

Browning, T.R., Deyst, J.J., Eppinger, S.D., Whitney, D.E., 2002. Adding value in product development by creating information and reducing risk. IEEE Trans. Eng. Manag. 49, 443-458.

Candi, M., Ende, J. van den, Gemser, G., 2013. Organizing innovation projects under technological turbulence. Technovation 33, 133-141.

Cantarelli, C.C., Flyvbjerg, B., Molin, E.J.E., van Wee, B., 2010. Cost Overruns in Large-scale Transportation Infrastructure Projects: Explanations and Their Theoretical Embeddedness. Eur. J. Transp. Infrastruct. Res. $10,5-18$.

Carson, S.J., Wu, T., Moore, W.L., 2012. Managing the Trade-off between Ambiguity and Volatility in New Product Development. J. Prod. Innov. Manag. 29, 1061-1081.

Denning, S., 2013. What went wrong at Boeing. Strateg. Leadersh. 41, 36-41.

Dezfuli, H., Stamatelatos, M., Maggio, G., Everett, C., Youngblood, R., 2010. Risk-Informed Decision Making (NASA/SP-2010-576). Office of Safety and Mission Assurance, NASA Headquarters.

Doctor, R.., Newton, D.., Pearson, A., 2001. Managing uncertainty in research and development. Technovation 21, 79-90.

DoD, 2006. Risk Management Guide for DoD Acquisition, 6th ed. United States Department of Defense, Office of the Secretary of Defense, Washington, D.C.

Fama, E.F., Macbeth, J.D., 1973. Risk, Return , and Equilibrium : Empirical Tests. J. Polit. Econ. 81, $607-636$.

Floricel, S., Ibanescu, M., 2008. Using R\&D portfolio management to deal with dynamic risk. R\&D Manag. 38, $452-467$.

Gallagher, B.P., 1999. Software Acquisition Risk Management Key Process Area (KPA) - A Guidebook. Software Engineering Institute, Pittsburgh, PA. 
GAO, 2006. Defense Acquisitions - Major Weapon Systems Continue to Experience Cost and Schedule Problems under DOD's Revised Policy (GAO 06-368). United States Government Accountability Office, Washington, D.C.

GAO, 2010. Defense Acquisitions - Managing Risk to Achieve Better Outcomes (GAO 10-374T). United States Government Accountability Office, Washington, D.C.

Graybill, F.A., 1976. Theory and application of the linear model. Duxbury Press, North Scituate, MA.

Greenacre, M., 2007. Correspondence Analysis in Practice, 2nd ed. Chapman \& Hall / CRC, Boca Raton.

Griffin, a., Hauser, J.R., 1992. Patterns of Communication Among Marketing, Engineering and Manufacturing A Comparison Between Two New Product Teams. Manage. Sci. 38, 360-373.

INCOSE, 2007. Systems Engineering Handbook v3.1. International Council on System Engineering, Seattle.

ISO, 2009. ISO 31000:2009(E) - Risk management - Principles and guidelines. International Organization for Standardization, Geneva.

Jacob, W.F., Kwak, Y.H., 2003. In search of innovative techniques to evaluate pharmaceutical R\&D projects. Technovation 23, 291-296.

Jiang, J., Klein, G., 2000. Software development risks to project effectiveness. J. Syst. Softw. 52, 3-10.

Jørgensen, M., Moløkken-Østvold, K., 2006. How large are software cost overruns? A review of the 1994 CHAOS report. Inf. Softw. Technol. 48, 297-301.

Keizer, J. a., Vos, J.-P., Halman, J.I.M., 2005. Risks in new product development: devising a reference tool. R\&D Manag. 35, 297-309.

Knight, F.H., 1921. Risk, uncertainty and profit. Houghton Mifflin, New York.

Krishnan, V., Ulrich, K.T., 2001. Product Development Decisions: A Review of the Literature. Manage. Sci. $47,1-21$.

Kwak, Y.H., LaPlace, K.S., 2005. Examining risk tolerance in project-driven organization. Technovation 25, 691-695.

Kwak, Y.H., Stoddard, J., 2004. Project risk management: lessons learned from software development environment. Technovation 24, 915-920.

Köhler, A.R., Som, C., 2013. Risk preventative innovation strategies for emerging technologies the cases of nano-textiles and smart textiles. Technovation.

Luce, R.D., Raiffa, H., 1957. Games and decisions: Introduction and critical survey. Wiley \& Sons.

Mu, J., Peng, G., MacLachlan, D.L., 2009. Effect of risk management strategy on NPD performance. Technovation 29, 170-180. 
O’Connor, G.C., Rice, M.P., 2013. A Comprehensive Model of Uncertainty Associated with Radical Innovation. J. Prod. Innov. Manag. 30, 2-18.

Oehmen, J., Ben-Daya, M., Seering, W., Al-Salamah, M., 2010. Risk Management in Product Design: Current State, Conceptual Model and Future Research, in: Volume 1: 36th Design Automation Conference, Parts A and B. ASME, pp. 1033-1041.

Oehmen, J., Oppenheim, B.W., Secor, D., Norman, E., Rebentisch, E., Sopko, J.A., Steuber, M., Dove, R., Moghaddam, K., McNeal, S., Bowie, M., Ben-Daya, M., Altman, W., Driessnack, J., 2012. The Guide to Lean Enablers for Managing Engineering Programs, Version 1. ed. Joint MIT-PMI-INCOSE Community of Practice on Lean in Program Management, Cambridge, MA.

Oehmen, J., Seering, W., 2011. Risk-Driven Design Processes - Balancing Efficiency with Resilience in Product Design, in: Birkhofer, H. (Ed.), The Future of Design Methodology. Springer, London.

OGC, 2009. Managing Successful Projects with PRINCE2. Office of Government Commerce, The Stationary Office, London.

Park, Y.H., 2010. A study of risk management and performance measures on new product development. Asian J. Qual. 11, 39-48.

Persson, J.S., Mathiassen, L., Boeg, J., Madsen, T.S., Steinson, F., 2009. Managing Risks in Distributed Software Projects : An Integrative Framework. IEEE Trans. Eng. Manag. 56, 508-532.

PMI, 2008. A guide to the project management body of knowledge (PMBOK guide), 4th ed. Project Management Institute, Drexel Hill, PA.

Raz, T., Shenhar, A.J., Dvir, D., 2002. Risk management, project success, and technological uncertainty. R\&D Manag. 32, 101-109.

Sicotte, H., Bourgault, M., 2008. Dimensions of uncertainty and their moderating effect on new product development project performance. R\&D Manag. 38, 468-479.

Song, W., Ming, X., Xu, Z., 2013. Risk evaluation of customer integration in new product development under uncertainty. Comput. Ind. Eng. 65, 402-412.

Swartz, S.M., 2008. Managerial perceptions of project stability. Proj. Manag. J. 39, 17-32.

Tang, C.S., Zimmerman, J.A., 2009. Managing New Product Development and Supply Chain Risks: The Boeing 787 Case. Supply Chain Forum An Int. J. 10, 74-86.

Thamhain, H., 2013. Managing Risks in Complex Projects. Proj. Manag. J. 44, 20-35.

Van de Vonder, S., Demeulemeester, E., Herroelen, W., Leus, R., 2005. The use of buffers in project management: The trade-off between stability and makespan. Int. J. Prod. Econ. 97, 227-240.

Wang, J., Lin, W., Huang, Y.-H., 2010. A performance-oriented risk management framework for innovative R\&D projects. Technovation 30, 601-611. 
Wheelwright, S.C., Clark, K.B., 1994. Accelerating the Design-build-test Cycle for Effective Product Development. Int. Mark. Rev. 11, 32-46.

Wirthlin, J.R., 2009. Identifying Enterprise Leverage Points in Defense Acquisition Program Performance. PhD Thesis, LAI and Massachusetts Institute of Technology.

Yeo, K.T., Ren, Y., 2008. Risk Management for Complex Product Systems ( CoPS ) Projects 12, $275-294$.

Yule, G.U., 1907. On the Theory of Correlation for any Number of Variables, Treated by a New System of Notation. Proc. R. Soc. A Math. Phys. Eng. Sci. 79, 182-193.

Zentis, T., Schmitt, R., 2013. Technical Risk Management for an Ensured and Efficient Product Development on the Example of Medical Engineering, in: Abramovici, M., Stark, R. (Eds.), Smart Product Engineering. Springer Berlin Heidelberg, Berlin, Heidelberg, pp. 387-398.

Zwikael, O., Ahn, M., 2011. The effectiveness of risk management: an analysis of project risk planning across industries and countries. Risk Anal. 31, 25-37. 